\title{
Original
}

\section{Spinal Cord Projections of the Upper Intercostal Nerve In the Rabbit Studied by Wheat Germ Agglutinin Conjugated Horseradish Peroxidase}

\author{
Katsunori INAGAKI $^{1)}$, Etsuo FUJIMAKI ${ }^{1)}$, Ikuo HoMma ${ }^{2)}$, \\ Michiko IWASE $^{2)}$ and Tetsuya HARA ${ }^{3)}$
}

\begin{abstract}
Spinal cord projections of the upper intercostal nerve in the rabbit were studied using axonal transport of wheat germ agglutinin conjugated horseradish peroxidase (WGA-HRP).

To label the spinal motoneurons, WGA-HRP was injected into three intercostal nerve branches: the external intercostal (EIC) nerve, and the medial (MIIC) and lateral (LIIC) branches of the internal intercostal nerve. The locations, the numbers and the soma size (average soma diameter) of 451 labeled motoneurons were analyzed in this study.

TMB reaction products were identified in the spinal cord from one and a half segments rostral to half a segment caudal to the entry segment. No reaction products were found on the contralateral side. Labeled motoneurons containing dense granular reaction products and their dendritic processes were located in the lateral portion of the ventral horn gray matter. Soma diameter ranged between $12 \mu \mathrm{m}$ and $45 \mu \mathrm{m}$ (average 23-25 $\mu \mathrm{m}$ ). Motoneurons labeled after injections into the three intercostal nerves (T4 or T5) overlapped extensively on transverse sections of ventral horn spinal cord. The results indicate that the LIIC nerve, which is neuroanatomically named the lateral cutaneous branch of the internal intercostal nerve, contains motor fibers originating from ventral horn motoneurons.
\end{abstract}

Key words: intercostal nerve, WGA-HRP, motoneuron, retrograde axonal transport

\section{Introduction}

The thoracic spinal nerve divides into the anterior and posterior branches distal to the joining of the anterior and posterior roots. The anterior branch immediately divides into the internal and external intercostal nerves. The internal intercostal nerve divides into its lateral (LIIC) and medial (MIIC) branches in the lateral chest wall area (Fig. 1).

The clinical usefulness of these nerves in the operation of intercostal nerve transfer ${ }^{1-4)}$ depends on the number of fibers, the length of the nerve and the distance between the suture point and the motor point. It is also essential to clarify the neurophysiological characteristics of these nerves. It has been considered that the LIIC nerve consists of somatosensory fibers

1) Department of Orthopaedic Surgery, Showa University School of Medicine, 1-5-8 Hatanodai, Shinagawa-ku, Tokyo 142, Japan.

2) Department of Physiology, Showa University School of Medicine.

3) Department of Orthopaedic Surgery, Tokyo Metropolitan Hiroo General Hospital. 


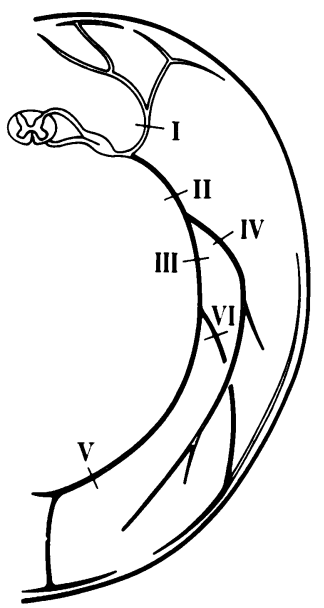

Fig. 1. Schematic drawing of a spinal nerve at the thoracic level showing sites of nerve transection.
I. dorsal ramus
II. intercostal nerve (ventral ramus)
III. internal intercostal nerve
IV. external intercostal nerve
V. medial branch from internal intercostal nerve
VI. lateral branch from internal intercostal nerve

from the skin. Therefore the LIIC nerve is usually not used in the intercostal nerve transfer operation. However, neurohistochemically, whether any motor fiber is included or not has not been studied.

In the present study, the spinal projection from the upper intercostal nerve was investigated in rabbits by the WGA-HRP method.

\section{Materials and Methods}

Experiments were performed on 12 adult female Japanese white rabbits weighing from 2.5 to $3.5 \mathrm{~kg}$. The animals were anesthetized with sodium pentobarbital (initial dose of 25 $\mathrm{mg} / \mathrm{kg}$ i.v.). Supplementary doses of pentobarbital were administered intraperitoneally during the course of each experiment as required. Before operating, each rabbit received local anesthesia of $1 \%$ lidocaine. The animals were placed in a semi-supine position. Under aseptic conditions, the intercostal nerve branch at the 4th or 5th segment was carefully isolated by microdissection. A piece of Parafilm was placed between the nerve and underlying tissue to prevent inadvertent uptake of WGA-HRP from this tissue.

Using a Hamilton syringe coupled to a glass micropipette with a 50-100 $\mu \mathrm{m}$ (internal diameter) tip, $10 \mu \mathrm{l}$ of $2 \%$ WGA-HRP solution was injected into the nerve. The entire working region was irrigated several times with saline and the wound was closed in layers. In 11 experiments; (1) 3 EIC, (2) 4 LIIC, (3) 3 MIIC, and (4) 1 internal intercostal nerve proximal to its division were injected with WGA-HRP (Fig. 1). In one control, no injection was made and the area surrounding the nerve was flooded with WGA-HRP solution.

After 72-96 hours survival the animals were deeply anesthetized and perfused through the left ventricle with 2 liters of normal saline, followed by 2 liters of fixative solution $(0.4 \%$ 
glutaraldehyde, 4\% paraformaldehyde). A thoracic laminectomy was performed (on each animal) and the spinal cord from mid-T1 to mid-T7, containing the injection site, was removed. The dura mater was cut and the spinal cord was stored in perfusate at $4^{\circ} \mathrm{C}$ overnight.

The fixed spinal cord was placed in a phosphate-buffered $5 \%$ sucrose solution, followed by $10 \%$ sucrose for $2-3$ hours, and $15 \%$ sucrose for 12 hours at $4{ }^{\circ} \mathrm{C}$. The spinal cord was cut serially into $30-70 \mu \mathrm{m}$ transverse sections, on a cryostat. Every section was processed for WGA-HRP neurohistochemistry with tetramethyl-benzidine (TMB). ${ }^{5-7}$ ) The sections were mounted on glass slides and air-dried overnight. Preparations with WGA-HRP labeling were counterstained with $2 \%$ neutral red. All spinal cord slides were carefully examined by light field microscopy for cells containing WGA-HRP reaction product.

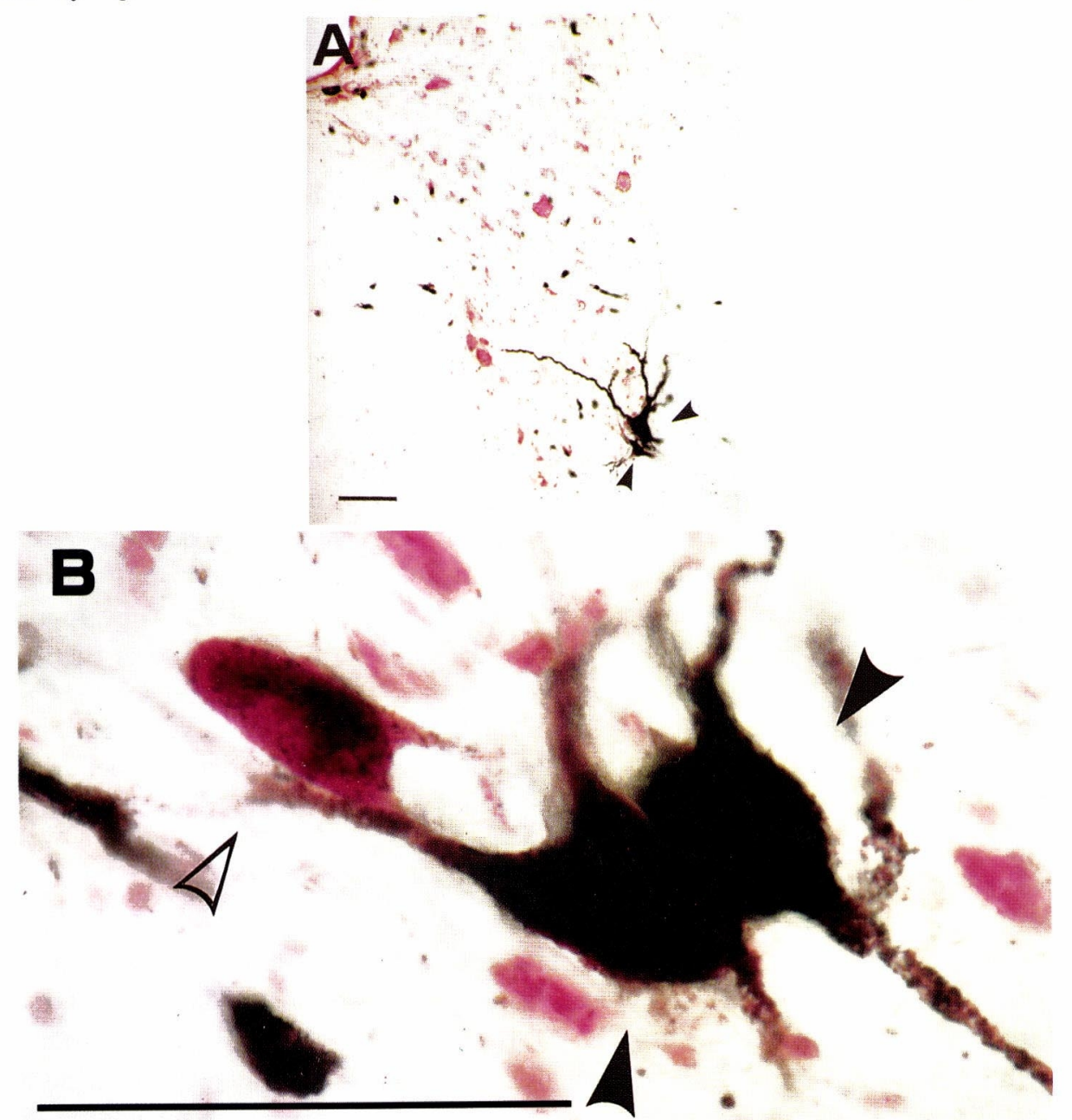

Fig. 2. A. Photomicrograph of transverse section (frozen, $60 \mu \mathrm{m}$ thick, neutral red counterstained) showing location of intercostal motor pool in extreme lateral portion of ventral horn. Motoneurons (arrows) were labeled by retrograde axonal transport of WGA-HRP applied to lateral branch of internal intercostal nerve. Scale bar $=100 \mu \mathrm{m}$.

B. The section at higher magnification (from another section). The larger multipolar-shaped cells (arrows), and a smaller nucleolated cell (open arrow). Scale bar $=50 \mu \mathrm{m}$. 


\section{Internal ICN External ICN}

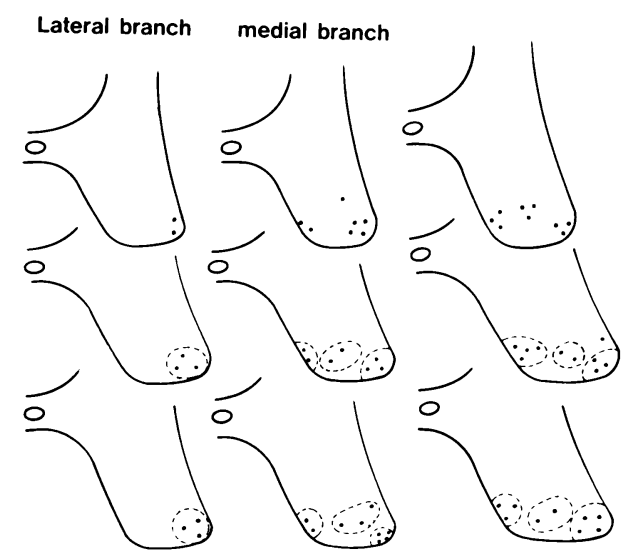

Fig. 3. Series of schematic transverse sections showing motoneurons labeled after application of WGA-HRP to each of the three intercostal nerve branches at the 4th or 5th thoracic segment of the spinal cord.

\section{Results}

WGA-HRP labeling of intercostal motoneurons

Dense granular deposits were identified along the axons of the intercostal nerves into which WGA-HRP was injected. No deposits were found in the adjacent non-injected intercostal nerve. Labeled motoneurons were seen in all cases in the ventral horn. A total of 451 cells were identified within the ventral horn. Anterogradely labeled dorsal horn cells were investigated in all cases, but in the present report, only labeling in the ventral horn is discussed. Labeled cells were restricted to the ipsilateral side. No reaction products were found in the contra-lateral side, which indicates that intercostal axons do not decussate in the cord.

Examples of WGA-HRP labeled motoneurons in the 5th thoracic spinal segment are given in the photomicrographs of Fig. 2. Cells of two different sizes were observed. The large cells were multipolar and heavily labelled throughout their soma and proximal dendrites. The smaller cells were fusiform and each contained a nucleus and granular reaction products.

\section{Localization and distribution of intercostal motoneurons}

Following the WGA-HRP injections into individual intercostal nerve branches, TMB reaction products were distributed in the spinal cord from one and a half segments rostral to half a segment caudal to the entry zone. In 10 experiments in which WGA-HRP was injected into each intercostal nerve branch, $80-100 \%$ of the stained cells were found in the spinal segment. And 0-20\% of the stained cells were found in the caudal half of the adjacent rostral segment and in the rostral half of the adjacent caudal segment. Fig. 3 shows, schematically, transverse views of the distribution of labeled motoneurons after application of WGA-HRP to the LIIC, MIIC and EIC nerves at the 4th or 5th thoracic segment of the spinal cord. As shown in Fig. 3, the cells were more scattered in the upper segment.

WGA-HRP was injected into the LIIC nerve in 4 experiments, and 140 labeled cells were identified. These were located almost exclusively (92.9\%) along the external border of the ventral horn. Only $7.1 \%$ of the cells were found in the middle of the ventral gray matter. 


\section{External ICN}
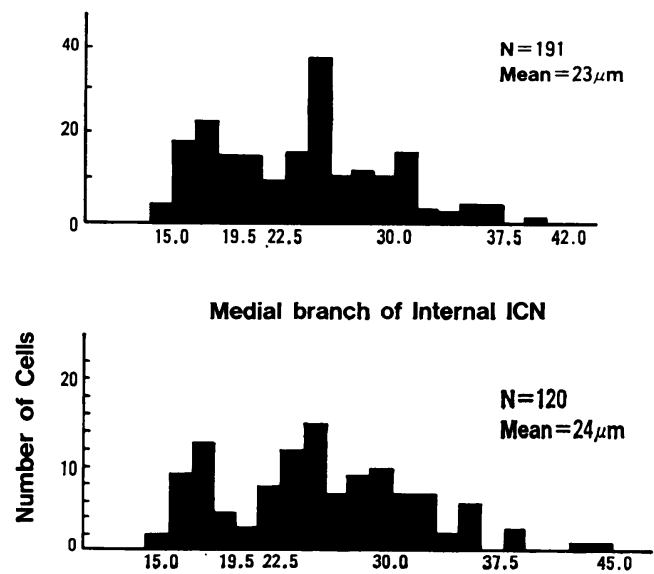

Lateral branch of Internal ICN

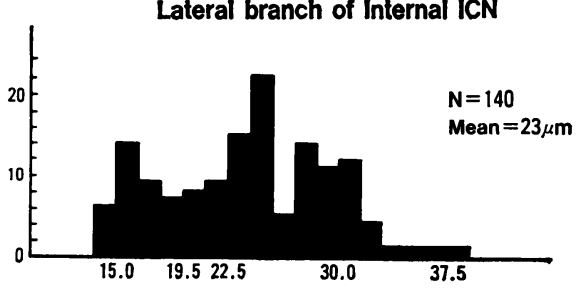

Average Soma Diameter $(\mu \mathrm{m})$

Fig. 4. Histograms of sizes of motoneurons (averages of maximum and minimum soma diameters) labeled after injections into each of three intercostal nerve branches.

In 3 experiments, WGA-HRP was injected into the MIIC nerve, and 120 labeled cells were identified. The MIIC motoneurons were widely distributed, with more in the medial zones of the ventral horn ( $15.8 \%$ of cells). Also, the MIIC motor column had a wider dorso-medial expanse than the LIIC motor column. Only $4 \%$ of the cells were found in the middle of the ventral gray matter.

After application of WGA-HRP to the EIC nerve in 3 experiments, 191 cells were observed. The EIC motoneurons are widely distributed, and seem to be more ventromedially located than the MIIC motor column.

Size and morphological characteristics of labeled intercostal motoneurons.

The maximum and minimum diameters of the nucleolated cells were measured with a microscope micrometer at a final magnification of $400 \times$. Large dendrites were eliminated by application of the imaginary oval technique ${ }^{8)}$ and no correction for cell shrinkage during fixation was attempted in this study.

Cell body diameters are plotted in the histograms in Fig. 4 for neurons labeled after injections into each of the three intercostal nerve branches. The average soma diameter ranged from 12 to $45 \mu \mathrm{m}$ with a peak between 23 and $25 \mu \mathrm{m}$ (mean \pm S.D: $\mathrm{LIIC}=23.0 \pm 5.5$, $\mathrm{MIIC}=23.9 \pm 6.0, \mathrm{EIC}=22.9 \pm 5.6$ ). The number of gamma-motoneurons is difficult to assess since the distributions of cell sizes did not show a clear bimodal distribution in the histo- 
grams. However, the average soma diameters of the MIIC motoneurons did seem to be distributed bimodally, with a transition between the small and large groups at about $21.0 \mu \mathrm{m}$.

\section{Discussion}

This study represents the first systematic investigation of spinal cord projections from the individual intercostal nerve branches. The use of WGA-HRP has been reported to be especially suitable for studying spinal cord projections from peripheral nerves. ${ }^{9,10}$ Since WGAHRP has been shown to be a more sensitive marker than free HRP for demonstrating spinal connections, ${ }^{11)}$ WGA-HRP was used in the present study. There have been very few other reports of studies of the intercostal nerve and muscle of the rabbit. Larnicol et al., ${ }^{12)}$ who injected free HRP into 4 individual intercostal muscles of the cat, described labeled intercostal motoneurons. Methodologically, there are two major techniques for injection of WGA-HRP in the periphery. One is intramuscular, ${ }^{5)}$ and the other is dipping the cut end of a nerve into a small plastic cup filled with HRP. However there are many technical problems in both of these procedures. One, especially true of intercostal nerves and muscles which are subjected to respiratory movement and its complex anatomical characteristics, is the technical error of leakage of enzyme to the periphery and its spread to other tissues, such as skin and nearby muscles. ${ }^{10,13,14)}$ Another problem is inadequate transport of WGAHRP, so that very few or no motor neurons contain enough HRP to be recognized as labeled. For these methodological considerations, we directly injected WGA-HRP into normal intercostal nerves using glass micropipettes. Special care was taken to prevent leakage of tracer into surrounding tissue during injection which was done under an operation microscope. Successful and adequate uptake of WGA-HRP into spinal cord gray matter was observed after this approach. During tissue analysis, since the axial length was between $40 \mu \mathrm{m}$ and $70 \mu \mathrm{m}$, repetitive counting of the same cell was avoided by aligning two successive sections. Thus, it is unlikely that the number of cells was overestimated.

The locations of labeled intercostal motoneurons agree with those reported for internal and external intercostal muscles restricted to the 3rd spinal thoracic level. ${ }^{12}$ Larnicol suggested that medially located intercostal motoneurons may be involved in postural functions while laterally located motoneurons may demonstrate intercostal muscle involvement in respiration. This also appears to apply in part to the EIC nerves, whose motoneurons are more medially located than the MIIC and LIIC nerves. Motoneurons labeled after injections into the EIC and MIIC nerves overlapped extensively in transverse sections of the ventral horn. In contrast, LIIC motoneurons were located mainly $(92.9 \%)$ in the lateral part of the ventral horn (Fig. 3).

Some afferent fibers (group Ia, Ib) cross through laminae I-III in their courses to deeper laminae. ${ }^{15)}$ Furthermore, projection of primary afferents centrally, and organization of lateral parts of lamina VII, as well as dorso-lateral lamina IX, are in good accordance with the typical distribution of group Ia afferents found in the cat. ${ }^{15}$ ) It is also possible that coarse primary afferent fibers influence motoneurons in the segment via interevening interneurons, although nothing seems to be known about the locations of such interneurons in the rabbit. ${ }^{16)}$ No WGA-HRP reaction products and no synaptic buttons ${ }^{15)}$ were identified in lamina VI and VII.

The cell bodies of intercostal motoneurons are in general smaller than the motoneurons that innervate the cat hindlimb, ${ }^{8)}$ forelimb, ${ }^{17)}$ or neck, ${ }^{14)}$ and are similar or larger than 
phrenic motoneurons. ${ }^{18-20)}$ Since it has been reported that gamma-motoneurons are systematically smaller in average soma diameter than alpha cells, ${ }^{21-23)}$ we assumed that cells with average diameters less than $21.0 \mu \mathrm{m}$ were gamma-motoneurons and that those with larger diameters were alpha-motoneurons in rabbit. Bimodal histograms of soma sizes in the MIIC nerves (Fig. 4) have been observed for hindlimb, ${ }^{8)}$ forelimb, ${ }^{17)}$ and neck ${ }^{24)}$ motoneurons. It is very interesting that the MIIC nerves used in the operation of intercostal nerve transfer to the musculocutaneous nerve have similar bimodal distributions to forelimb nerve and muscle. The small-diameter cells are considered to be gamma-motoneurons. ${ }^{25)}$ In contrast, in the LIIC and EIC nerves, we could identify no significant peak in cell size which might correspond to gamma-motoneurons (Fig. 4). One factor that has been suggested to possibly contribute to this discrepancy is the relative impermeability of spindle capsules to HRP. ${ }^{12,14,26)}$ It is also possible, that relatively larger gamma-motoneurons and smaller alpha motoneurons might be the reasons for the unimodal histograms.

In summary, this study has provided a detailed description of the location of intercostal motoneurons. The results indicate that the LIIC nerve also includes motor fibers orginating from ventral horn motoneurons.

\section{References}

1) Seddon HJ: Nerve grafting. J Bone Joint Surg, 45: 447-461 (1963)

2) Tsuyama $\mathrm{N}$ and Hara $\mathrm{T}$ : Intercostal nerve transfer in the treatment of brachial plexus injury of rootavulsion type. Orthopaedic surgery and traumatology. In: Proceedings of the 12th Congress of the International Society of Orthopaedic Surgery and Traumatology, Excerpta Medica, Amsterdam, pp 912 (1972)

3) Tsuyama N, Hara $\mathrm{T}$ and Nagano A: Intercostal nerve crossing as a treatment of irrepairably damaged whole brachial plexlus. In: Recent Developments in Orthopaedic Surgery, Noble J and Galasko CSB (Eds), Manchester University Press, Manchester, UK, pp 169-174 (1987)

4) Takahashi M: Studies on conversion of motor function in intercostal nerves crossing for complete brachial plexus injuries of root avulsion type. J Jpn Orthop Assoc, 57: 139-147 (1983)

5) Mesulam M-M: Tetramethyl benzidine for horseradish peroxidase neurohistochemistry: a non-carcinogenic blue reaction product with superior sensitivity for visualizing neural afferents and efferents. J Histochem Cytochem, 26: 106-117 (1978)

6) Mesulam M-M and Brushart TM: Transganglionic and anterograde transport of horseradish peroxidase across dorsal root ganglia: a tetramethylbenzidine method for tracing central sensory connections of muscles and peripheral nerves. Neuroscience, 4: 1107-1117 (1979)

7) Mesulam M-M, Hegarty E, Barbas H, Carson KA, Gower EC, Knapp AG, Moss MB and Mufson EJ: Additional factors influencing sensitivity in the tetramethyl benzidine method for horseradish peroxidase neurohistochemistry. J Histochem Cytochem, 28: 1255-1259 (1980)

8) Burke RE, Strick PL, Kanda K, Kim CC and Walmsley B: Anatomy of medial gastrocnemius and soleus motor nuclei in cat spinal cord. J Neurophysiol, 40: 667-680 (1977)

9) Brushart TM and Mesulam MM: Alteration in connections between muscle and anterior horn motor neurons after peripheral nerve repair. Science, 208: 603-605 (1980)

10) Molander $C$ and Grant G: Spinal cord projections from hindlimb muscle nerves in the rat studied by transganglionic transport of horseradish peroxidase, wheat germ agglutinin conjugated horseradish peroxidase, or horseradish peroxidase with dimethylsulfoxide. J Comp Neurol, 260: 246-255 (1987)

11) Nicholas KC, Clive H, Tomohiko $M$ and Jacqueline OG: Superior sensitivity of conjugates of horseradish peroxidase with wheat germ agglutinin for studies of retrograde axonal transport. J Histochem Cytochem, 27: 728-734 (1979)

12) Larnicol N, Rose D, Marlot D and Duron B: Anatomical organization of cat intercostal motor nuclei as demonstrated by HRP retrograde labeling. J Physiol (Paris), 78: 198-206 (1982)

13) Nyberg G and Blomqvist A: The somatotopic organization of forelimb cutaneous nerves in the brachial dorsal horn: an anatomical study in the cat. J Comp Neurol, 242: 28-39 (1985) 
14) Richmond FJR, Scott DA and Abrahams VC: Distribution of motoneurons to the neck muscles, biventes cervicis, splenius and complexus in the cat. J Comp Neurol, 181: $451-464$ (1978)

15) Brown AG: Organization in the Spinal Cord. Springer Verlag, Berlin (1981)

16) Burke RE, Walmsley B and Hodgson JA: HRP anatomy of group Ia afferent contacts on alpha motoneurones. Brain Res, 160: 347-352 (1978)

17) Jenny AB and Inukai J: Principles of motor organization of the monkey cervical spinal cord. $J$ Neurosci, 3: 567-575 (1983)

18) Rikard-Bell GC and Bystrzycka EK: Localization of phrenic motor nucleus in the cat and rabbit studied with horseradish peroxidase. Brain Res, 194: 479-483 (1980)

19) Rikard-Bell GC, Bystrzycka EK and Nail BS: The identification of brainstem neurons projecting to thoracic respiratory motoneurons in the cat as demonstrated by retrograde transport of HRP. Brain Res Bull, 14: 25-37 (1985)

20) Webber CL Jr, Wurster RD and Chung JM: Cat phrenic nucleus architecture as revealed by horseradish peroxidase mapping. Exp Brain Res, 35: 395-406 (1979)

21) Burke RE, Dum RP, Fleshman JW, Gleen LL, Lev-Tov A, O'Donovan MJ and Pinter MJ. An HRP study of the relation between cell size and motor unit type in cat ankle extensor motoneurons. J Comp Neurol, 209: 17-28 (1982)

22) Bryan RN, Trevino DL and Willis WD: Evidence for a common location of alpha and gamma motoneurons. Brain Res, 38: 193-196 (1972)

23) Westbury DR: A comparison of the structures of alpha and gamma spinal motoneurones of the cat. J Physiol (Lond), 325: 79-91 (1982)

24) Abrahams VC and Keane $\mathbf{J}$ : Contralateral, midline, and commissural motoneurons of neck muscles: A retrograde HRP study in the cat. J Comp Neurol, 223: 448-456 (1984)

25) Lagerback P-A: An ultrastructural study of cat lumbosacral gamma-motoneurons after retrograde labeling with horseradish peroxidase. J Comp Neurol, 240: 256-264 (1985)

26) Miller AD: Localization of motoneurons innervating individual abdominal muscles of the cat. $J$ Comp Neurol, 256: 600-606 (1987)

[Received September 22, 1989: Accepted October 19, 1989] 